\title{
Lentes fácicas de câmara anterior
}

\author{
Anterior chamber phakic lenses
}

Walton Nosé1, Adriana dos Santos Forseto²

\begin{abstract}
ReSUMO
Os implantes em olhos fácicos apresentam-se como uma opção para a correção de altas ametropias. De acordo com sua localização podem ser classificados como de câmara anterior ou posterior, sendo que os primeiros subdividem-se em fixação iriana ou de suporte angular. Além da correção da miopia, as lentes de fixação iriana apresentam modelos para hipermétropes e astigmatas. Várias modificações no desenho das lentes foram propostas nas últimas décadas com a finalidade de reduzir complicações tardias, como a perda endotelial progressiva. Cuidados no intraoperatório devem ser tomados de forma a diminuir a perda endotelial aguda relacionada ao trauma. Avanços nos métodos de triagem pré-operatória também melhoraram a segurança do procedimento. A estimativa do poder dióptrico é baseada nos cálculos de Van der Heijde, sendo dependente da profundidade de câmara anterior, do equivalente esférico da refração e da média ceratométrica. Resultados a longo prazo demonstram a eficácia, previsibilidade e segurança do procedimento. Dependendo do modelo, além da possibilidade de perda endotelial, outras possíveis complicações incluem: irite, dispersão pigmentar, atrofia de íris, ovalização pupilar, rotação, descentração ou deslocamento da lente, hipertensão ocular e bloqueio pupilar. Modelos dobráveis atualmente disponíveis vêm apresentado resultados bastante promissores com redução da taxa de complicações.

Descritores: Lentes intraoculares fácicas; câmara anterior; erros de refração; procedimentos cirúrgicos refrativos; complicações intraoperatórias; complicações pós-operatórias
\end{abstract}

\begin{abstract}
The phakic intraocular lenses (pIOLs) are a good option for the correction of high refractive errors. According to their anatomical position there are two types of pIOLs: anterior or posterior chamber. The anterior chamber pIOL may be iris-fixated or angle-supported. The iris-fixated pIOLs are available not only for myopia correction, but also for hyperopia and astigmatism. During the last decades many modifications on the pIOLs designs were proposed in order to reduce late complications, such as progressive endothelial cell loss. Acute endothelial cell trauma related to the surgical procedure may be minimized with proper intraoperative care. Advances in the preoperative screening methods have improved the safety of the procedure. Estimation of the pIOL power is based on the van der Heijde calculations and is dependent on the anterior chamber depth, the spherical equivalent and the mean keratometric values. Long-term results show the efficacy, predictability and safety of the procedure. According to the type of the pIOL, complications other than endothelial cell loss include iritis, pigment dispersion, iris atrophy, pupil ovalization, pIOL rotation, decentration or dislocation, intraocular pressure elevation and pupillary block glaucoma. Foldable models actually available show promising results with lower complication rate.

Keywords: Phakic intraocular lenses; anterior chamber; refractive errors; refractive surgical procedures; intraoperative complications; postoperativa complications
\end{abstract}

\footnotetext{
1 Universidade Federal de São Paulo (UNIFESP), São Paulo (SP), Brasil;

${ }^{2}$ Universidade Federal de São Paulo (UNIFESP); São Paulo (SP), Brasil.
}

Instituição: Eye Clinic Day Hospital, São Paulo, Brasil

Os autores declaram inexistir conflitos de interesse

Recebido para publicação em 5/4/2011 - Aceito para publicação em 26/11/2011 


\section{INTRODUÇÃO}

$\mathbf{O}$ s implantes intraoculares em olhos fácicos vêm se destacando no que se refere à correção cirúrgica das altas ametropias, principalmente pelas vantagens que apresentam em relação aos procedimentos refrativos na córnea, como o LASIK (laser in situ keratomileusis) e a PRK (ceratectomia fotorrefrativa), e outros intra oculares, como a extração de cristalino transparente.

O tratamento de altas ametropias com procedimentos fotoablativos requer a remoção de grande quantidade de tecido corneano, aumentando o risco de ectasias em correções miópicas, altera a asfericidade da córnea e apresenta previsibilidade e estabilidade reduzidas ${ }^{(1)}$. Com a extração de cristalino transparente temos perda da acomodação e maior risco de descolamento de retina e edema macular cistóide, principalmente após a realização de capsulotomia posterior com Nd:Yag laser ${ }^{(2)}$.

$\mathrm{O}$ efeito refrativo obtido com os implantes fácicos é influenciado pelo cálculo do poder dióptrico da lente implantada, por variações no astigmatismo pós-operatório e alterações no comprimento axial dos olhos. Além disto, este procedimento cirúrgico é considerado previsível, reversível e de certa forma, ajustável, preservando também a acomodação dos pacientes.

De acordo com o modelo, os implantes fácicos podem ser implantados na câmara anterior ou posterior, sendo que o primeiro grupo subdivide-se em suporte angular e fixação iriana. Conforme resolução do Conselho Federal de Medicina (CFM) de abril de 2008 (Processo-Consulta CFM no 4296/2007 - Parecer CFM no 6/ 08), os implantes de lentes intraoculares de fixação iriana foram aprovados no Brasil para correção de altas ametropias (miopia e hipermetropia) e afacias.

O objetivo deste trabalho é fornecer uma revisão da literatura mundial sobre os resultados obtidos com os diferentes implantes de lentes fácicas de câmara anterior disponíveis na atualidade.

\section{Lentes fácicas de câmara anterior de suporte angular}

A idéia de se utilizar lentes intraoculares (LIOs) fácicas de câmara anterior para correção de altas ametropias surgiu na década de 50, com Strampelli e Barraquer $^{(3,4)}$.Tratavam-se de lentes de suporte angular, tendo sido observadas complicações associadas ao seu formato, como descompensação corneana, iridociclite crônica e hifema, responsável pela indicação de explante
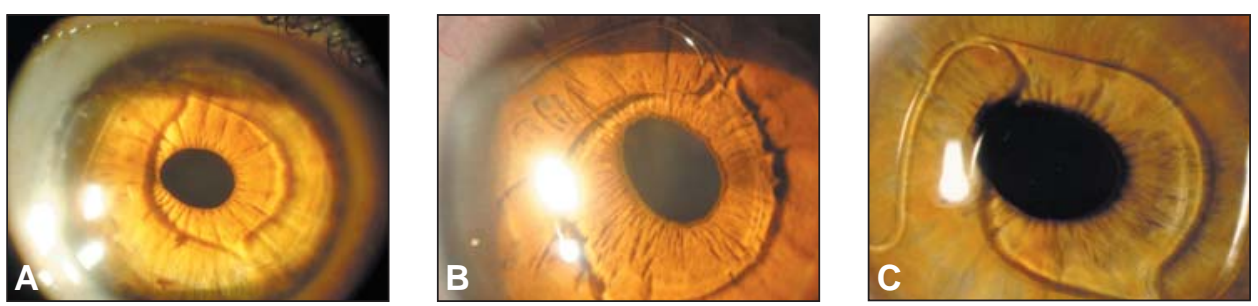

Figura 1: Diferentes estágios de retração de íris e ovalização de pupila (a, b, c, d) com implantes fácicos de câmara anterior de suporte angular; observe a relação da pupila com a parte óptica da LIO

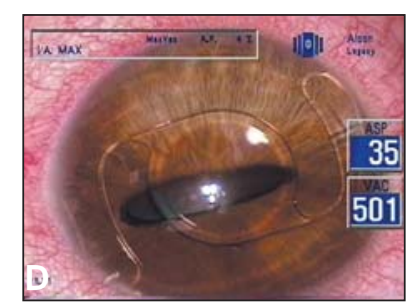

em grande parte dos casos ${ }^{(5)}$. Com o passar dos anos foram realizadas modificações, possibilitando novamente a utilização deste tipo de implante ${ }^{(6)}$.

Durante as décadas de 80 e 90, vários modelos de lentes de suporte angular de polimetilmetacrilato (PMMA) foram desenvolvidos e implantados, tendo sido posteriormente retirados do mercado pela presença de complicações inaceitáveis. Alguns modelos chegaram a ser implantados no Brasil por meio de protocolos universitários, como a ZB 5M (Domilens Corp) ${ }^{(7,8)}$ e a NuVita MA 20 (Bausch \& Lomb) ${ }^{(9,10)}$. Apesar dos bons resultados refracionais e ganho de melhor acuidade visual com correção (chegando a $65 \%$ de ganho de duas ou mais linhas da melhor acuidade visual corrigida) ${ }^{(7-9)}$, a ovalização pupilar progressiva era uma complicação relativamente frequente. Em um estudo com seguimento de 5 anos, De Souza et al. reportaram este tipo de complicação em até $46,1 \%$ dos $\operatorname{casos}^{(7)}$ (Figura 1). A perda endotelial em um estudo com 12 anos de seguimento com implante do modelo ZB5M foi de 10,6\% durante o primeiro ano, seguida de uma redução anual média de $1,8 \%{ }^{(11)}$. A perda com o modelo NuVita MA20 foi de $12 \%$ nos primeiros 12 meses segundo estudo de Allemann et al., estabilizando-se até os 24 meses $^{(9)}$.

Mudanças no material das lentes foram sugeridas, de forma a se obter maior flexibilidade, provavelmente reduzindo-se a incidência de retração pupilar. Os modelos Vivarte/GBR (Ioltech) e I-Care (Corneal Laboratories, Inc.) apresentaram resultados iniciais promissores, mas foram retirados do mercado em 2006 e 2008 , respectivamente, por problemas relacionados à perda endotelial ${ }^{(12)}$.

A LIO Acrysof Cachet (Alcon laboratories, Inc., Forth Worth, TX, EUA), recentemente lançada no Brasil (agosto de 2010) é uma LIO de peça única, de material acrílico hidrofóbico (o mesmo já utilizado há anos em cirurgia de catarata pelo mesmo fabricante), dobrável, e de suporte angular, para correção de miopia. Apresenta óptica de $6,00 \mathrm{~mm}$ e comprimento total de 12,50 a 14,00mm, estando disponível na faixa de $-6,00$ a $-16,50$ dioptrias (D), com incrementos de 0,50D (Figura 2). Seus hápticos foram desenhados de forma a gerar uma força de compressão sutil na região angular, ocasionando estabilidade da LIO, sem ser excessiva o suficiente para gerar danos teciduais locais ou ovalização pupilar. O arco ou "vault" da LIO é pequeno (inferior a $0,50 \mathrm{~mm}$ ) fazendo com que haja uma distância segura e estável entre o endotélio e cristalino ${ }^{(13,14)}$. Este tipo de lente já foi registrado pela ANVISA e aprovado para uso pela 


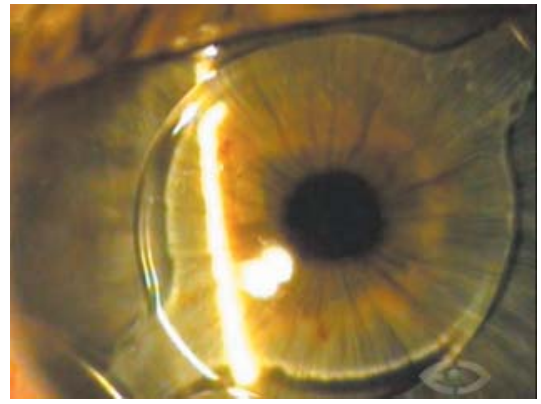

Figura 2: Pós-operatório de LIO fácica dobrável de câmara anterior de suporte angular de peça única (Acrysof Cachet,Alcon Inc.)
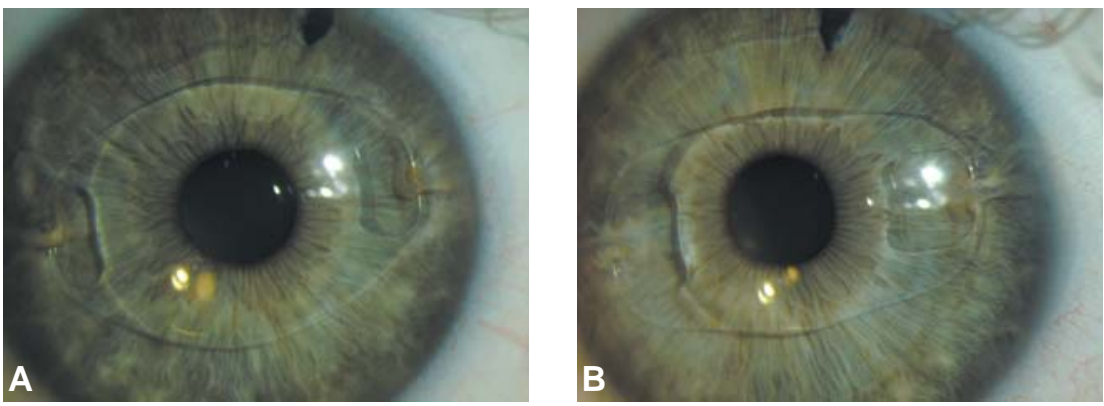

Figura 3 (a e b): Pós-operatório de LIO fácica de câmara anterior de fixação iriana (Artisan, Ophtec BV) com óptica de 6,00mm (3a) e 5,00mm (3b)
Europa (CE marking, do francês "Conformité Européenne") e encontra-se na fase III de estudos do Food and Drug Administration (FDA) nos Estados Unidos (15) com previsão de aprovação de registro para junho de 2011, de acordo com dados obtidos com o fabricante. Seus resultados de 1 e 3 anos já foram publicados, sendo estes bastante promissores $(13,14,16)$.

\section{Lentes fácicas de câmara anterior de fixação na íris}

As lentes de câmara anterior de fixação na íris, também conhecidas como "iris claw lens" foram inicialmente desenhadas por Worst para correção cirúrgica da afacia, apresentando a vantagem do não-contato com as estruturas do ângulo. Os modelos iniciais eram presos superiormente à íris por meio de uma sutura de aço, e inferiormente pela fixação em garra, de forma a prevenir angulação anterior da lente. Posteriormente, o princípio de fixação em garra ou encravamento à íris foi incorporado aos dois hápticos da lente ${ }^{(17)}$. Em 1986, Fechner et al criaram uma lente bicôncava para correção de alta miopia, baseada na já existente "iris claw lens", usada em cirurgias de catarata ${ }^{(18)}$. Em 1990, esta configuração bicôncava original foi modificada para um desenho convexo-côncavo, de forma a reduzir os riscos de complicações, melhorar os resultados visuais e facilitar o procedimento cirúrgico ${ }^{(19)}$.

Atualmente, as lentes de fixação iriana são produzidas e distribuídas pela Ophtec BV (Groningen, Holanda) ou pela Abbott Medical Optics, Inc. (Illinois, EUA), sendo conhecidas como lentes Artisan ou Verisyse, respectivamente. Trata-se de uma lente de peça única, não dobrável, constituída de PMMA com filtro ultravioleta, cujos hápticos dispostos simetricamente apresentam uma pequena falha na qual realizamos o encravamento da meia periferia da íris de forma estável, permitindo a manutenção da constrição e dilatação pupilar. Apresenta a vantagem de ser centralizada na pupila do paciente e a versatilidade de poder ser fixada na posição horizontal, vertical ou oblíqua. Encontra-se disponível para correção de miopia, hipermetropia e astigmatismo. O arco ("vault") da porção óptica é de aproximadamente $0,87 \mathrm{~mm}$, proporcionando uma distância segura do endotélio e cristalino ${ }^{(12)}$. Todos os modelos apresentam diâmetro total de $8,50 \mathrm{~mm}$, sendo uma van- tagem em relação às de suporte angular que necessitam da correta avaliação pré-operatória da medida do diâmetro da câmara anterior, uma vez que estas ficam apoiadas no ângulo.

Dois modelos estão disponíveis para correção de miopia de acordo com diâmetro da parte óptica: modelo 206 (óptica de 5,00 mm; poder dióptrico de $-1,00$ a $-23,50$ $\mathrm{D}$, em incrementos de $0,50 \mathrm{D}$ ), e modelo 204 (óptica de 6,00 mm; poder dióptrico de $-1,00$ a $-15,50 \mathrm{D}$, em incrementos de 0,50 D) (Figura 3). As lentes para a correção de hipermetropia, assim como as tóricas, apresentam óptica de 5,00 mm, com poder dióptrico entre $+1,00$ e $+12,00 \mathrm{D}$ (incrementos de $0,50 \mathrm{D}$ ). Os modelos tóricos possuem poder dióptrico esférico entre +12,00 e -23,50D (incrementos de $0,50 \mathrm{D}$ ), com adicional cilíndrico de 1,00 a 7,50 (incrementos de $0,50 \mathrm{D})$, sendo orientadas a $0^{\circ}$ ou $90^{\circ(20,21)}$. Modelos para correção da afacia também estão disponíveis, com dimensões semelhantes aos da hipermetropia, e poder dióptrico variando de $+2,00$ a $+30,00 \mathrm{D}$.

As lentes para correção da miopia apresentam maior espessura na periferia, ao contrário das hipermetrópicas, cuja maior espessura é na região central. Desta forma, as LIOs miópicas necessitam de uma maior profundidade de câmara anterior para manterem uma distância segura do endotélio(12).

Um modelo dobrável desta lente de fixação à íris também encontra-se disponível (Artiflex, Ophtec ou Veriflex, Abbott Medical Optics, Inc.). Sua parte óptica de 6,00mm de diâmetro é constituída de polisiloxane hidrofóbico, com poder dióptrico entre -2,00 e -14,50D, em incrementos de 0,50D, e seus hápticos de PMMA (Figura 4).

\section{Avaliação pré-operatória}

A avaliação pré-operatória é de fundamental importância para seleção dos pacientes e também para o cálculo da LIO a ser implantada. Deve ser o mesmo para qualquer tipo de cirurgia refrativa, incluindo uma avaliação oftalmológica completa, com medidas da acuidade visual com e sem correção, refração dinâmica e estática, biomicroscopia à lâmpada de fenda, tonometria, ceratometria, topografia corneana, microscopia especular, análise da profundidade e do diâmetro da câmara anterior, do diâmetro pupilar, dominância ocular e mapeamento de retina.

A estimativa do poder dióptrico da LIO é reali- 


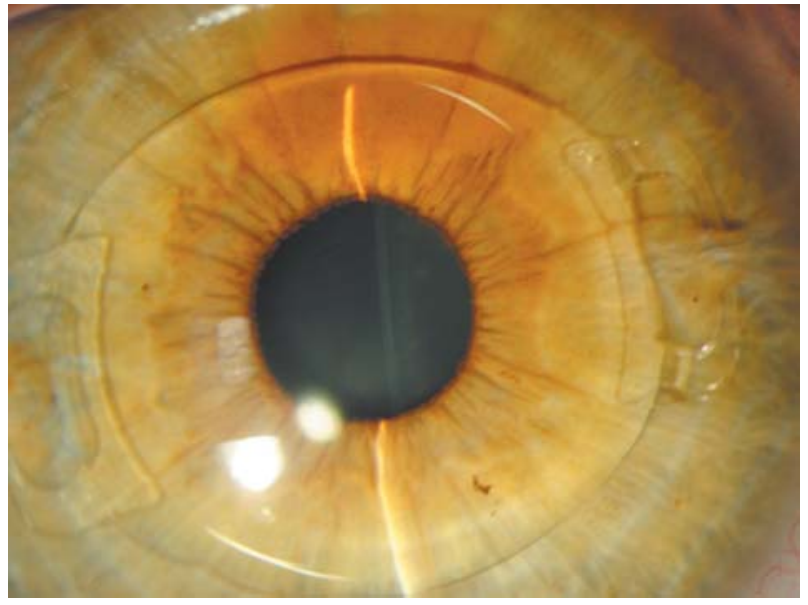

Figura 4: Pós-operatório de LIO fácica dobrável de câmara anterior de fixação iriana (Artiflex, Ophtec BV)

zado de acordo com programas fornecidos pelo fabricante, baseadas nos cálculos de van der Heijde, sendo independente do comprimento axial do bulbo ocular, mas dependente da profundidade de câmara anterior, do equivalente esférico da refração e da média ceratométrica ${ }^{(18,22)}$.

Ao contrário das lentes de suporte angular, o comprimento total das lentes de fixação iriana é fixo $(8,50$ $\mathrm{mm}$ ), sendo na maioria das vezes dispensável a medida do diâmetro interno do ângulo da câmara anterior. Para as lentes de suporte angular, esta medida, antigamente estimada a partir da distância externa de branco-a-branco, pode ser obtida indiretamente por alguns tipos de topógrafos e alguns biômetros ópticos, ou diretamente pela biomicroscopia ultrassônica ou tomografia de coerência óptica do segmento anterior (23) (Figura 5). Falhas na correta aferição do diâmetro da câmara anterior pode levar a hipo ou hipercompressão da LIO, aumentando ou reduzindo o seu arco ou "vault" ideal. O modelo da LIO Acrysof Cachet é escolhido de acordo com este diâmetro segundo orientações do fabricante (Tabela 1).

A medida da profundidade da câmara anterior é de extrema importância, estando diretamente relacio-

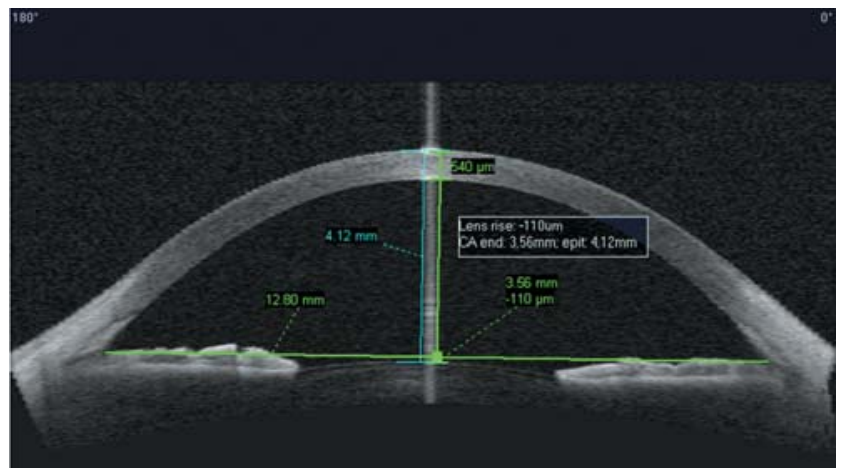

nada à segurança do procedimento. Estudos já mostram correlação significante entre perda endotelial e câmaras anteriores mais rasas $^{(24)}$. Geralmente o mínimo aceitável é de 3,00 a 3,20mm do endotélio da córnea até a região central da cápsula anterior do cristalino ${ }^{(15)}$. Outros preconizam uma profundidade mínima de câmara anterior de $3,20 \mathrm{~mm}$ a partir do epitélio ou $2,70 \mathrm{~mm}$ a partir do endotélio ${ }^{(12,25)}$.

Outra medida de extrema importância fornecida pela tomografia de coerência óptica do segmento anterior é o grau de anteriorização do cristalino, ou "crystalline lens rise" $(\mathrm{CLR})^{(26)}$. Esta medida é calculada através da distância entre o pólo anterior do cristalino e a linha que mede o diâmetro horizontal da câmara anterior (Figura 5). Ao analisar casos de dispersão pigmentar em pacientes com lentes Artisan, Baikoff et al. observaram que o CLR limítrofe de segurança é de $600 \mu \mathrm{m}$. Através desta medida, os autores propuseram uma fórmula que permite estimar o tempo durante o qual um implante fácico poderia permanecer dentro do olho do paciente sem risco de dispersão pigmentar, levando-se em consideração um crescimento médio anual do cristalino de 18 a $20 \mu \mathrm{m}$. O tempo (T), em anos, seria calculado subtraindo-se o valor de CLR atual do paciente do valor limítrofe de segurança $(600 \mu \mathrm{m})$, e dividindo-se por $20 \mu \mathrm{m}$ (taxa anual de crescimento do cristalino). Assim sendo, em um paciente com $200 \mu \mathrm{m}$ de CLR atualmente, a fórmula seria: $T=(600-200) / 20=20$ anos ${ }^{(26)}$.

Apesar de alguns autores utilizarem como critério de exclusão valores de densidade endotelial de 2.000 céls/mm ${ }^{2}(25,27)$, esta deve ser analisada em função da idade do paciente por ocasião do implante ${ }^{(15)}$. Este valor mínimo deve considerar a perda endotelial natural que ocorre durante o processo de envelhecimento de forma a assegurar transparência da córnea e valores $\geq 1.000$ céls $/ \mathrm{mm}^{2}$ aos $75 \operatorname{anos}^{(15)}$. Os valores mínimos de densidade endotelial utilizados como critérios para aprovação do FDA para as lentes Verisyse ou Artisan, e de estudos para a LIO Cachet estão demonstrados na tabela $2^{(13)}$. No Brasil, o valor mínimo preconizado pela resolução do CFM para as LIOs de fixação iriana é de 2.000 céls $/ \mathrm{mm}^{2}$ (Processo-Consulta CFM no 4296/2007 - Parecer CFM n' 6/08).

O diâmetro pupilar em condições de baixa iluminação deve preferencialmente ser inferior ao da parte

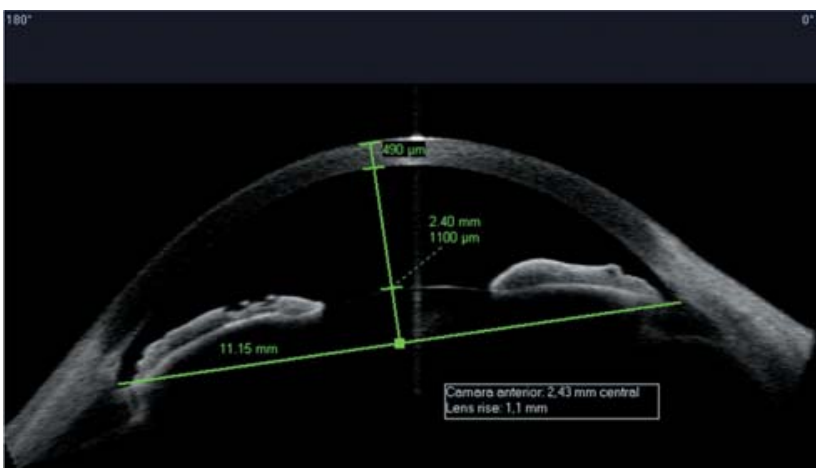

Figuras 5: Medidas de diâmetro, profundidade da câmara anterior (CA) e "crystalline lens rise" (CLR) fornecidas pelo tomógrafo de coerência óptica OCT Visante (Carl Zeiss Meditec, Inc.). Figura 5a: alta miopia com profundidade de CA a partir do endotélio de $3,56 \mathrm{~mm}$ e CLR de $-110 \mu \mathrm{m}$. Figura 5b: alta hipermetropia e CLR de $+1.100 \mu \mathrm{m}$ 
Tabela 1

Modelo da LIO Acrysof Cachet conforme as medidas fornecidas de diâmetro da câmara anterior

\begin{tabular}{cc}
\hline $\begin{array}{c}\text { Diâmetro da câmara } \\
\text { anterior }(\mathbf{m m})\end{array}$ & Modelo da LIO \\
\hline 11,25 a 11,75 & $\mathrm{~L} 12500$ \\
11,76 a 12,25 & $\mathrm{~L} 13000$ \\
12,26 a 12,75 & $\mathrm{~L} 13500$ \\
12,76 a 13,25 & $\mathrm{~L} 14000$ \\
\hline
\end{tabular}

Tabela 2

Densidade endotelial em função da idade como critério de seleção para implante de lente fácica, de acordo com o FDA ${ }^{(13)}$

\begin{tabular}{|c|c|c|c|}
\hline \multicolumn{2}{|c|}{ LIO Artisan } & \multicolumn{2}{|c|}{ LIO Cachet } \\
\hline $\begin{array}{l}\text { Faixa etária } \\
\text { (anos) }\end{array}$ & $\begin{array}{l}\text { Densidade endotelial } \\
\text { mínima (céls/mm²) }\end{array}$ & $\begin{array}{l}\text { Faixa etária } \\
\text { (anos) }\end{array}$ & $\begin{array}{l}\text { Densidade endotelial } \\
\text { mínima (céls } / \mathbf{m m}^{2} \text { ) }\end{array}$ \\
\hline $21-25$ & 3.550 & $18-25$ & 2.800 \\
\hline $26-30$ & 3.175 & $26-35$ & 2.600 \\
\hline $31-35$ & 2.825 & $36-45$ & 2.200 \\
\hline $36-40$ & 2.500 & $\geq 46$ & 2.000 \\
\hline $41-45$ & 2.225 & - & - \\
\hline$>45$ & 2.000 & - & - \\
\hline
\end{tabular}

Fonte: http://www.accessdata.fda.gov/cdrh_docs/pdf3/P030028b.pdf

óptica da LIO, para reduzir queixas subjetivas de visão de halos e ofuscamentos. Astigmatismos pré-operatórios podem ser em parte reduzidos pelo posicionamento da incisão no meridiano mais curvo, pelo controle da tensão da sutura no caso de lentes não dobráveis, ou pela associação com procedimentos fotoablativos como o LASIK em um segundo tempo, técnica conhecida como Bioptics, inicialmente descrita após implantes fácicos de câmara posterior ${ }^{(28)}$.

Por vezes, o implante das lentes Artisan em altas hipermetropias fica restrito em função da câmara anterior rasa que estes pacientes geralmente apresentam. Entretanto, pacientes com hipermetropias secundárias a outros procedimentos refrativos, como por exemplo a ceratotomia radial, normalmente possuem câmara anterior profunda, podendo se beneficiar com a técnica ${ }^{(29)}$.

\section{Técnica cirúrgica}

Independentemente do modelo de LIO, as cirurgias podem ser realizadas sob anestesia tópica associada à sedação, dependendo da experiência do cirurgião, devendo ser utilizado um balão de Honan como preparo pré-operatório por aproximadamente dez minutos, com a finalidade de reduzir a pressão vítrea.

Lentes fácicas de câmara anterior de fixação na íris A incisão tunelizada, geralmente límbica, é feita na posição das 12 horas, medindo entre 5,25 e $6,25 \mathrm{~mm}$, de acordo com o diâmetro da óptica da LIO a ser implantada. Pode ser deslocada para o meridiano mais curvo de forma a auxiliar na correção do astigmatismo. Duas paracenteses são realizadas paralelas à incisão principal.

A pupila é fechada com auxílio de miótico e a câmara anterior é preenchida com substância viscoelástica coesiva. A lente é inserida na câmara anterior (Figura 6a) e rodada horizontalmente de forma a ficar centralizada sobre a pupila do paciente. Uma sutura de mononylon 10-0 é posicionada centralmente na incisão principal para manter a câmara anterior formada. A seguir procede-se a fixação da lente à íris, segurando-a com o auxílio de uma pinça pela incisão principal, e realizando-se o encravamento de parte do tecido da meia periferia da íris ao háptico com um cistítimo, através de uma das paracenteses (Figura 6b). O mesmo procedimento é realizado com o háptico contralateral.

Procede-se o fechamento da incisão com mais dois pontos separados de mononylon 10-0. Caso não tenha sido realizada iridotomia profilática no pré-operatório, é mandatória a realização de iridectomia no ato cirúrgico. Ao término do procedimento a substância viscoelástica precisa ser removida, podendo ser utilizadas canetas de irrigação e aspiração separadas introduzidas pelas paracenteses (Figura 6c).

No caso da lente Artiflex (modelo dobrável), a 
Tabela 3

Eficácia e previsibilidade de alguns estudos de implantes fácicos de câmara anterior de suporte angular e fixação iriana ${ }^{13,16,25,27,30,31)}$

\begin{tabular}{|c|c|c|c|c|c|c|c|c|c|c|}
\hline \multirow[t]{2}{*}{ Autor / ano } & \multirow[t]{2}{*}{ LIO } & \multirow[t]{2}{*}{$\mathbf{n}$} & \multirow[t]{2}{*}{$\begin{array}{l}\text { Seguimento } \\
\text { (anos) }\end{array}$} & \multicolumn{2}{|c|}{$\begin{array}{c}\text { Eq Esf } \\
\text { Médio (D) }\end{array}$} & \multicolumn{2}{|c|}{$\begin{array}{c}\text { Eq Esf } \\
\text { pós-op (\%) }\end{array}$} & \multicolumn{2}{|c|}{$\begin{array}{c}\text { AV s/c } \\
\text { pós-op (\%) }\end{array}$} & \multirow{2}{*}{$\begin{array}{c}\text { Índice } \\
\text { de }\end{array}$} \\
\hline & & & & Pré & Pós & $\mathbf{\pm 0 , 5 0}$ & $\pm 1,00$ & $\geq 20 / 20$ & $\geq 20 / 40$ & \\
\hline Budo et al., 2000 & Artisan & 249 & 3 & $-12,95$ & $-0,6$ & 57,1 & 78,8 & 33,7 & 76,8 & 1,03 \\
\hline \multirow{3}{*}{ Güell et al., 2008} & Artisan $5 \mathrm{~mm}$ & 101 & 0,25 a 5 & $-19,8$ & $-0,50$ & 9,9 & 22,8 & 0 & 14,8 & 0,86 \\
\hline & & 173 & & $-11,27$ & $-0,64$ & 37,6 & 57,2 & 2,9 & 42,8 & 0,74 \\
\hline & ArtisanHiper & 41 & 0,25 a 5 & $+4,92$ & $+0,02$ & 34,8 & 64,2 & 0 & 42,8 & 0,9 \\
\hline Stulting et al., 2008 & Artisan & 662 & $<1$ a 3 & $-12,3$ & $\mathrm{NC}$ & 71,7 & 94,7 & $34,6^{*}$ & $88^{*}$ & $\mathrm{NC}$ \\
\hline Dick et al., 2009 & Artiflex & 290 & 2 & $-7,33$ & $-0,15$ & 75,2 & 94,3 & $\mathrm{NC}$ & 97,2 & 1,00 \\
\hline Kohnen et al., 2009 & Cachet & 190 & $1(\mathrm{n}=161)$ & $-10,38$ & $-0,23$ & 72,7 & 95,7 & 57,8 & 99,4 & $\mathrm{NC}$ \\
\hline Knorz et al., 2011 & Cachet & 360 & $3(\mathrm{n}=104)$ & $-10,41$ & $-0,24$ & 78,8 & 91,3 & 46,2 & 97,1 & $\mathrm{NC}$ \\
\hline
\end{tabular}

eq esf (equivalente esférico); n (numero de casos); D (dioptrias); AV (acuidade visual); s/c (sem correção); Índice de Eficácia (média da AV s/c pós-operatória dividida pela média da AV com correção pré-operatória); NC (não consta);

(*)considerados apenas os casos cujo objetivo era emetropia pós-operatória $(n=434)$

\section{Tabela 4}

Dados de segurança de alguns estudos de implantes fácicos de câmara anterior de suporte angular e fixação iriana $(13,16,25,27,30,31)$

\begin{tabular}{|c|c|c|c|c|c|c|c|c|c|}
\hline \multirow[t]{2}{*}{ Autor / ano } & \multirow[t]{2}{*}{ LIO } & \multirow[t]{2}{*}{$\mathbf{n}$} & \multirow{2}{*}{$\begin{array}{l}\text { Seguimento } \\
\text { (anos) }\end{array}$} & \multicolumn{5}{|c|}{ Alteração AV c/c (\%) } & \multirow{2}{*}{$\begin{array}{l}\text { Índice de } \\
\text { Segurança }\end{array}$} \\
\hline & & & & $\begin{array}{c}\text { Perda } \\
\geq 2 L\end{array}$ & $\begin{array}{l}\text { Perda } \\
\text { 1L }\end{array}$ & $\mathbf{0} \mathbf{L}$ & $\begin{array}{c}\text { Ganho } \\
1 \mathrm{~L}\end{array}$ & $\begin{array}{c}\text { Ganho } \\
\geq 2 \mathrm{~L}\end{array}$ & \\
\hline Budo et al, 2000 & Artisan & 249 & 3 & 1,2 & 2 & 53 & & 44 & 1,03 \\
\hline \multirow[t]{3}{*}{ Güell et al, 2008} & Artisan $5 \mathrm{~mm}$ & 101 & 0,25 a 5 & $\mathrm{NC}$ & $\mathrm{NC}$ & $\mathrm{NC}$ & $\mathrm{NC}$ & $\mathrm{NC}$ & 1,3 \\
\hline & Artisan6mm & 173 & 0,25 a 5 & $\mathrm{NC}$ & $\mathrm{NC}$ & $\mathrm{NC}$ & $\mathrm{NC}$ & $\mathrm{NC}$ & 1,04 \\
\hline & ArtisanHiper & 41 & 0,25 a 5 & $\mathrm{NC}$ & $\mathrm{NC}$ & $\mathrm{NC}$ & $\mathrm{NC}$ & $\mathrm{NC}$ & 1,25 \\
\hline Stulting et al, 2008 & Artisan & 662 & $<1$ a 3 & 1,8 & 6,6 & 38,6 & 40,4 & 13,6 & $\mathrm{NC}$ \\
\hline Dick et al, 2009 & Artiflex & 290 & 2 & 0 & 9 & 51 & 33 & 7 & 1,09 \\
\hline Kohnen et al, 2009 & Cachet & 190 & $1(\mathrm{n}=161)$ & 0 & 1,2 & 44,7 & 31,1 & 23 & 1,25 \\
\hline Knorz et al, 2011 & Cachet & 360 & $3(\mathrm{n}=104)$ & 0,9 & 0,9 & 38,5 & 40,4 & 19,2 & 1,21 \\
\hline
\end{tabular}

n (número de casos); AV (acuidade visual); c/c (com correção); índice de segurança (média da AV c/c pós-operatória dividida pela média da $\mathrm{AV}$ c/c pré-operatória); NC (não consta).

incisão pode ser de $3,20 \mathrm{~mm}$, uma vez que ela é inserida através de uma espátula própria (Figura 7). A principal diferença aqui é que a parte óptica não deve ser manipulada com pinça para não ser danificada. $O$ encravamento deve ser realizado segurando-se a LIO pela transição entre a óptica e o háptico.

Lentes fácicas de câmara anterior de suporte angular Inicialmente, a LIO deve ser inserida dentro do cartucho (modelo P ou B, Alcon laboratories, Inc., sendo que até o momento apenas este último encontra-se disponível no Brasil) através de uma técnica especial de modo a não danificá-la (Figura 8). Após a sua montagem no ejetor (Monarch II ou III, do mesmo fabricante), procedese com a abertura da incisão (geralmente de $2,75 \mathrm{~mm}$ para o cartucho B) e a paracentese, cuja localização será de acordo com a preferência do cirurgião. Aqui também utilizamos miótico e viscoelástico coesivo. A LIO é ejetada dentro da câmara anterior e após confirmação do posicionamento adequado da mesma (principalmente se não está invertida), o viscoelástico é exaustivamente removido e a incisão checada quanto a possíveis vazamentos, sendo suturada caso necessário (Figura 9).

No pós-operatório, geralmente utilizamos uma associação de corticóide e antibiótico tópico por período de 30 dias com redução gradativa, e hipotensor tópico por cinco dias.

\section{Resultados clínicos}

De maneira geral, as lentes fácicas de câmara 

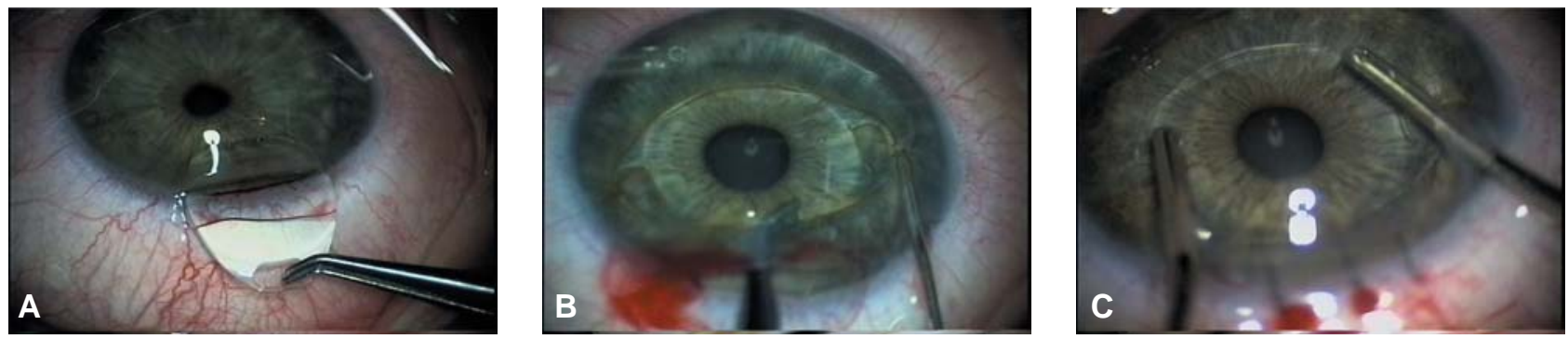

Figura 6:Técnica cirúrgica de lente de fixação iriana (Artisan, Ophtec BV) 6a: inserção da LIO pela incisão principal; 6b: encravamento do tecido da meia periferia da íris ao háptico da lente; 6c: irrigação bimanual da substância viscoelástica ao término do procedimento

anterior apresentam bons resultados ao se analisar a eficácia e previsibilidade. A Tabela 3 mostra os resultados de maior seguimento publicados na literatura mundial com os implantes fácicos de câmara anterior atualmente disponíveis no Brasil (13,16,25,27,30,31).

Os resultados dos diferentes estudos devem ser sempre analisados criticamente. Por vezes, o erro refracional é superior à capacidade de correção do implante, sendo esperado um residual esférico ou mesmo cilíndrico, o que reduz os dados de eficácia e previsibilidade. No estudo de Güell et al., por exemplo, cirurgia refrativa complementar na córnea foi realizada em 61 dos 101 olhos (60,39\%) com implante miópico de $5,00 \mathrm{~mm}$, sendo que $75 \%$ destes $(\mathrm{n}=48)$ já haviam sido previamente programados com os pacientes antes do implante ${ }^{(31)}$.

O ganho de acuidade visual corrigida, geralmente observado nos pós-operatórios de implantes de lentes intraoculares para correção miópica, parece estar relacionado ao aumento da imagem ao nível da retina que ocorre nestes pacientes ${ }^{(32)}$. Em estudo prospectivo, comparativo e randomizado entre as técnicas de LASIK e implante de lentes Artisan para correção de miopia entre -8,00 e $12,00 \mathrm{D}$, Malecaze et al. encontraram previsibilidade semelhante com os dois procedimentos analisados. Entretanto, maior ganho de acuidade visual corrigida foi observado com os implantes, traduzido em índice de segurança significantemente melhor neste último grupo ${ }^{(33)}$. Os implantes também foram os preferidos em relação à técnica de LASIK quanto à melhor qualidade visual em estudo realizado por El Danasoury et al. ${ }^{(34)}$.

Em um estudo prospectivo e multicêntrico europeu foram implantadas 518 lentes Artisan, tendo sido obtido seguimento completo de três anos em 249 olhos $(48,1 \%)^{(30)}$. Os pacientes foram divididos em grupos conforme a ametropia pré-operatória: grupo I, miopia moderada $(5,00$ a $10,00 \mathrm{D} ; \mathrm{n}=69)$; grupo II, alta miopia $(11,00$ a $15,00 \mathrm{D}$; $\mathrm{n}=120$ ); e grupo III, miopia extrema (> 15,00 D; $\mathrm{n}=60)$. Manutenção ou melhora da melhor acuidade visual corrigida foi obtida por $95,8 \%$ dos olhos. Houve diferença estatisticamente significante em termos de ganho de linhas de visão entre os três grupos analisados. No grupo III $63,3 \%$ dos casos ganharam duas ou mais linhas, contra $43,7 \%$ do grupo II, e $23,5 \%$ do grupo I. No geral, três olhos $(1,2 \%)$ perderam duas ou mais linhas da melhor acuidade visual corrigida (um pelo aparecimento de catarata nuclear e os outros dois sem causa aparente). Intervenção cirúr-

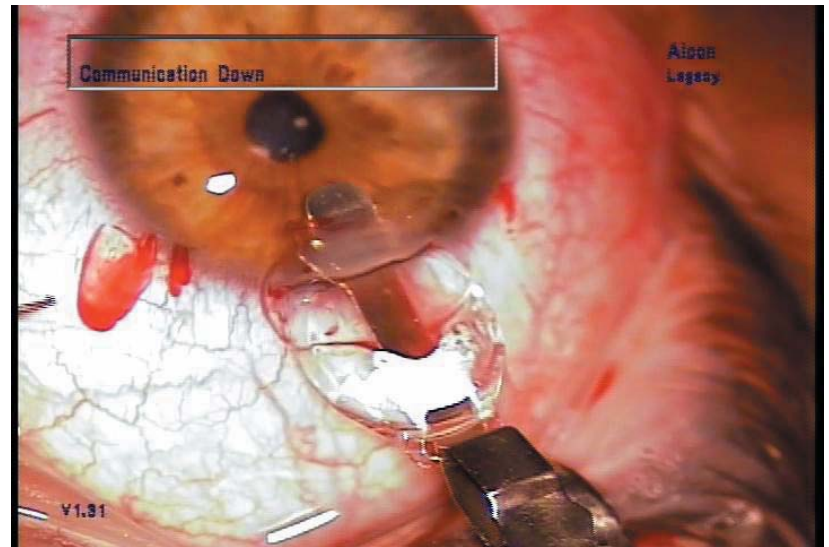

Figura 7: Inserção da lente de fixação iriana dobrável (Artiflex) na câmara anterior pela incisão principal, com espátula

gica secundária foi necessária em 22 olhos e incluiu reposicionamento de lente descentrada $(n=5)$, explante da lente $(n=7)$; troca da lente $(n=8)$; reposicionamento de hérnia de íris $(\mathrm{n}=1)$ e correção de astigmatismo por PRK $(\mathrm{n}=1)$ ${ }^{(30)}$. A Tabela 4 mostra os resultados em relação à segurança dos implantes fácicos de câmara anterior.

\section{Complicações:}

Irite

Como as lentes fácicas de câmara anterior são posicionadas diretamente à frente da íris, pode ocorrer inflamação crônica e dispersão pigmentar durante o movimento pupilar ${ }^{(35)}$. Casos de explante com modelos anteriores de LIO de suporte angular por inflamação crônica já foram reportados na literatura ${ }^{(9,36)}$. Os resultados de 3 anos de seguimento com a LIO Acrysof Cachet são bastante promissores, não tendo sido reportados irite ou edema macular cistóide durante o período analisado, porém há descrição de sinéquias em $1,7 \%$ dos casos ${ }^{(16)}$.

Por ser presa à íris, as lentes Artisan podem evoluir com processo inflamatório agudo ou crônico da câmara anterior. Menezo et al. não observaram extravasamento de contraste em estudo angiográfico da íris de olhos implantados com este tipo de lente, aos exames de seis, 12 e 24 meses de pós-operatório ${ }^{(37)}$. Fechner et al também não observaram extravasamento vascular nos olhos implantados e avaliados com angiografia fluorescente de íris. Porém, a análise por 

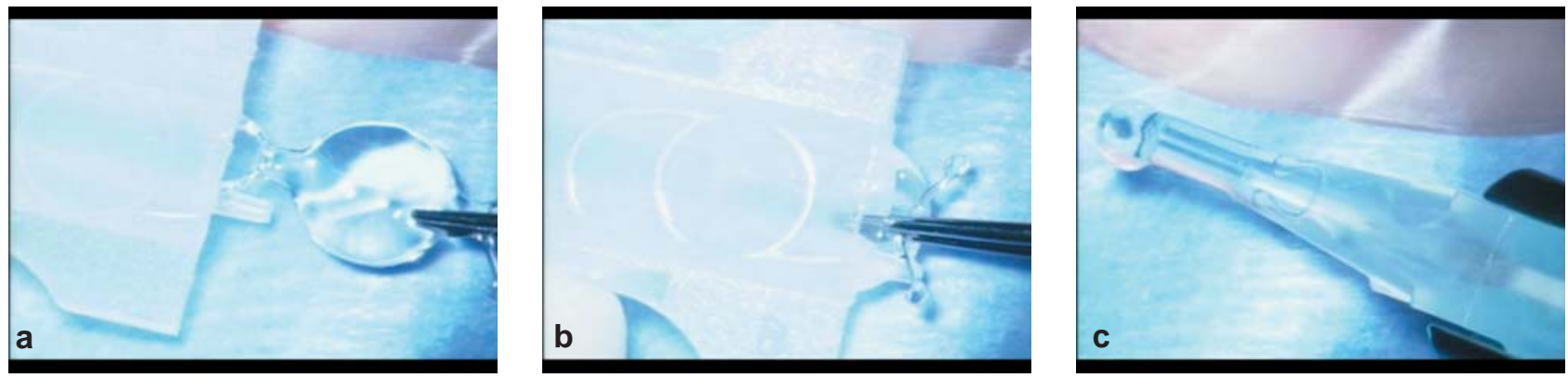

Figura 8 (a, b, c): Passos da inserção da LIO de suporte angular dobrável Acrysof Cachet no cartucho

um medidor a laser de reação de câmara anterior mostrou uma inflamação de mesma magnitude do que a observada após cirurgia extracapsular de catarata com implante de lente no saco capsular, até o sexto mês de pós-operatório ${ }^{(38)}$. Por sua vez, Pérez-Santonja et al. demonstraram inflamação crônica considerada subclínica entre um e dois anos de pósoperatório de implante de lente de fixação iriana ${ }^{(39,40)}$. Stulting et al. observaram inflamação pós-operatória transitória (células e flare na câmara anterior) em $40,3 \%$ dos casos de implante de Artisan no primeiro dia de pós-operatório (classificada como severa em apenas $0,3 \%$ ), tendo sido reduzido para 8,3\% na segunda semana e 3,6\% no segundo mês ${ }^{(27)}$. Explante de LIO Artisan por irite crônica recorrente não responsiva a tratamento associada a sinéquias posteriores também já foi relatada ${ }^{(41)}$. Formação de sinéquia foi reportada em 1,4\% dos casos com implante de LIO Artiflex em seguimento de dois anos ${ }^{(25)}$.

Nos trabalhos aqui apresentados não foram encontrados relatos de edema macular cistóide em implantes fácicos de fixação iriana. Edema macular com este tipo de lente já foi relatado quando para correção de afacia, mas sem diferenças estatisticamente significantes em comparação à fixação escleral de lente intraocular ${ }^{(42)}$.

\section{Alteração endotelial}

Segundo alguns autores, as lentes de suporte angular teriam uma maior tendência à perda de células endoteliais pelas dificuldades da escolha do seu diâmetro (relacionada à medida do diâmetro da câmara anterior). Lentes hipodimensionadas podem apresentar rotação intraocular, com maior possibilidade de inflamação e até toque endotelial ${ }^{(15)}$. A perda média de células endoteliais de pacientes implantados com a LIO Cachet entre o período pré e pós-operatório de 6 meses foi de
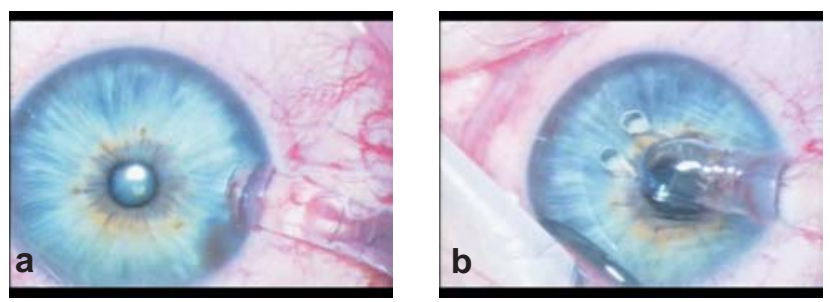

Figura 9: Técnica cirúrgica da lente de suporte angular dobrável (Acrysof Cachet); 9a: ejetor na incisão; 9b e 9c: parte do cartucho na área pupilar e ejeção da LIO na câmara anterior; 9d: posicionamento dos hápticos; 9e: remoção do viscoelástico; 9f: aspecto final

$3,31 \%$ na região central e $2,98 \%$ na periférica, tendo sido superior a $10 \%$ em $10,6 \%$ dos casos. Durante este período inicial as perdas tendem a ser relacionadas ao trauma cirúrgico. A perda média tardia anualizada (entre 6 meses e 3 anos) foi de $0,41 \%^{(16)}$.

A perda endotelial observada com os implantes de lentes Artisan parece estar mais relacionada ao ato cirúrgico, também sendo maior ao exame de seis meses de pós-operatório, com tendência à redução desta taxa nos exames seguintes ${ }^{(43)}$. Correlação já foi demonstrada não só entre a perda de células endoteliais e profundidade reduzida de câmara anterior ${ }^{(24,43)}$, mas também com implantes mais espessos ${ }^{(43)}$. Landesz et al. observaram perda endotelial média de $5,5 \%$ ao exame de seis meses, 7,2\% aos 12 meses, 9,1\% aos 24 meses, e 10,9\% aos 36 meses. Segundo estes autores a perda observada neste período foi estatisticamente progressiva, entretanto aqui eles não conseguiram encontrar correlação com os valores de profundidade de câmara anterior ${ }^{(44)}$. Budo et al. acompanharam o endotélio de 129 olhos implantados com as lentes Artisan por período de 3 anos. Maior perda endotelial foi observada nos primeiros seis meses (redução de 4,8\%). Perdas adicionais, mas em menor intensidade foram encontradas nos demais seguimentos (um ano: 2,4\%; dois anos: 1,7\%; e três anos: 0,7\%) ${ }^{(30)}$. Resultados semelhantes foram observados no estudo americano de 3 anos de seguimento com perda média de $-4,8 \% \pm 7,8 \%{ }^{(27)}$. Em um dos estudos com maior seguimento com a LIO Artisan, Güell et al. encontraram perda média de $11,3 \%$ aos 5 anos ${ }^{(31)}$. Neste estudo, explante da LIO foi necessário em 3 casos $(0,75 \%)$ por perda endotelial inaceitável, tendo sido provavelmente relacionada ao ato de coçar os olhos (31) (Figura 10). A perda aos 2 anos de pós-operatório com a LIO Artiflex foi de $-1,07 \% \pm 16,35 \%{ }^{(25)}$.
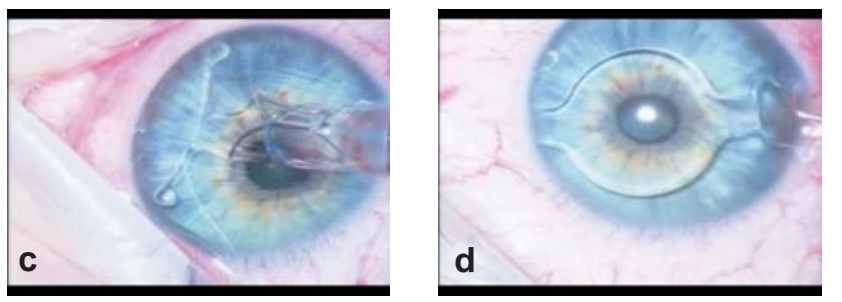


\section{Dispersão pigmentar e depósitos na LIO}

Casos de dispersão pigmentar e depósitos na LIO são raramente reportados com os implantes de suporte angular, mas podem ocorrer, sendo que raramente afetam a visão ${ }^{(35)}$.

A dispersão pigmentar tende a ocorrer com maior frequência nos pacientes com lentes de fixação iriana, sendo o grau de anteriorização do cristalino (crystalline lens rise) um fator de risco ${ }^{(26)}$.

Pigmentos irianos assintomáticos são frequentemente observados no endotélio da córnea ou na superfície da LIO em pacientes com lentes Artisan. Foram encontrados em $6,8 \%$ dos casos no primeiro ou segundo dia de pós-operatório; em 9,4\% entre o primeiro e segundo mês; em $6,9 \%$ entre os meses 4 e 6 , com redução progressiva até completa ausência ao pós-operatório de 3 anos (27). Para as lentes Artiflex, os precipitados pigmentados foram reportados em 4,8\% dos casos no pós-operatório de 2 anos, sem significado clínico. Neste mesmo estudo, precipitados não pigmentados foram encontrados em $1,4 \%$ dos olhos $(n=4)$, tendo sido descritos como células gigantes, sendo necessário tratamento em apenas um dos casos, por perda de 4 linhas da melhor acuidade visual corrigida. Após uso de corticosteróide tópico, o paciente atingiu visão de 20/20 em exame subsequente ${ }^{(25)}$.

\section{Ovalização pupilar}

A ovalização pupilar tende a ocorrer com maior freqüência nas lentes de suporte angular pelo próprio posicionamento de seus hápticos, principalmente quando a LIO foi hiperdimensionada. Conforme previamente relatado, nos modelos rígidos, a taxa de ovalização chegou a ser reportada como sendo de $46,1 \%$ no seguimento de 5 anos ${ }^{(7)}$. A ovalização pupilar pode acentuar a queixa de visão de halos, que tende a ocorrer quando os centros ópticos da LIO e da pupila não são coincidentes, ou quando o diâmetro pupilar escotópico é significantemente maior que a óptica da LIO ${ }^{(35)}$. Os resultados de 3 anos com a LIO Cachet são bastante promissores não tendo sido reportados casos de ovalização pupilar ${ }^{(16)}$. Cabe aqui ressaltar o provável papel do material da LIO na redução deste tipo de complicação, mas também da melhoria no cálculo do diâmetro da câmara anterior (importante para o dimensionamento da LIO) com as novas tecnologias disponíveis.

Complicação rara com as lentes de fixação iriana, a ovalização pode ocorrer caso o encravamento dos hápticos na íris seja realizado de maneira assimétrica. Nesta situação, geralmente é diagnosticado no momento da cirurgia, em tempo hábil para sua correção. $\mathrm{O}$ mecanismo é diferente do observado com as lentes de suporte angular, com as quais há uma ovalização progressiva da pupila ${ }^{(16)}$. Distorção pupilar assintomática foi reportada em $13 \%$ dos olhos com lentes Artisan no pósoperatório de 1 dia, tendo sido observada em apenas 1 caso aos 3 anos $(0,4 \%)^{(27)}$.

\section{Catarata}

A catarata desenvolvida no pós-operatório de implantes fácicos de câmara anterior geralmente está relacionada ao trauma cirúrgico, com toque no cristali- no. Vacúolos no cristalino foram observados no pós-operatório de quatro casos $(3,1 \%)$ operados no estudo de Maloney et al., sendo causados, segundo os autores, por trauma direto na cirurgia ou pelo viscoelástico utilizado ${ }^{(45)}$. Estudos demonstraram haver uma distância segura entre a LIO e o cristalino, o que parece reduzir o aparecimento deste tipo de complicação ${ }^{(38)}$. Desenvolvimento de catarata relacionada à idade foi observada por $2,4 \%$ dos casos com lentes Artisan por Budo et al. ${ }^{(30)}$.

Idade acima de 40 anos na época da cirurgia e comprimento axial superior a $30,00 \mathrm{~mm}$ foram considerados fatores significantemente relacionados ao desenvolvimento de catarata nuclear em paciente com implantes fácicos de suporte angular ${ }^{(46)}$ (Figura 11). No seguimento de 1 ano com as lentes Cachet foram reportados 5 casos de desenvolvimento de catarata $(2,63 \%)$, tendo sido associado ao posicionamento invertido da LIO na câmara anterior (upside-down) em 2 casos ${ }^{(13)}$. Em outro estudo, com maior seguimento, a taxa de formação de catarata foi de $1,9 \%{ }^{(16)}$.

Recente estudo de meta-análise sobre desenvolvimento de catarata após implantes fácicos mostrou uma incidência de 1,29\% para as LIOs de câmara anterior de suporte angular; de 1,11\% para as de fixação iriana, e de $9,60 \%$ para as de câmara posterior. A média de tempo para o aparecimento da catarata foi de 33,1 meses e 37,6 meses para as lentes de suporte angular e fixação iriana, respectivamente ${ }^{(47)}$.

\section{Retina}

A presença da LIO não dificultou a observação da periferia da retina no estudo de Fechner et al., sendo possível a realização de fotocoagulação profilática em dois casos que necessitaram deste tratamento no acompanhamento pós-operatório. Outro caso evoluiu com descolamento de retina após uma semana de cirurgia, tendo sido submetido à cirurgia e apresentado restabelecimento dos níveis de acuidade visual pré-operatórios ${ }^{(38)}$. Pérez-Santonja consideraram a análise da periferia da retina mais difícil após implante das lentes de fixação iriana, não tendo observado nenhum caso de descolamento ${ }^{(40)}$. Até o momento, nenhum caso de descolamento de retina foi relatado após implante da LIO Cachet $(13,16)$. Descolamento de retina foi encontrado em $0,51 \%$ dos casos (6/1.179) com implante de LIO Artisan no estudo de Stulting et al., o que corresponderia a uma taxa aproximada de $0,3 \%$ por olho por ano, e segundo os autores semelhante a taxa observada em estudos sobre descolamento de retina em olhos com alta miopia e sem cirurgia refrativa prévia ${ }^{(27)}$.

\section{Rotação, descentração e deslocamento da LIO}

Rotação é uma complicação geralmente associada às lentes de suporte angular, quando estas apresentam um diâmetro menor que o ideal. No estudo de 1 ano com a LIO Cachet, a maioria dos casos $(67,4 \%)$ apresentou rotação $\leq 15^{\circ}$ em relação ao primeiro controle. Quando a rotação foi comparada entre visitas, 71,1\% dos olhos nunca apresentaram rotação superior a $15^{\circ} \mathrm{em}$ relação às consultas anteriores ${ }^{(13)}$. A rotação da LIO po- 


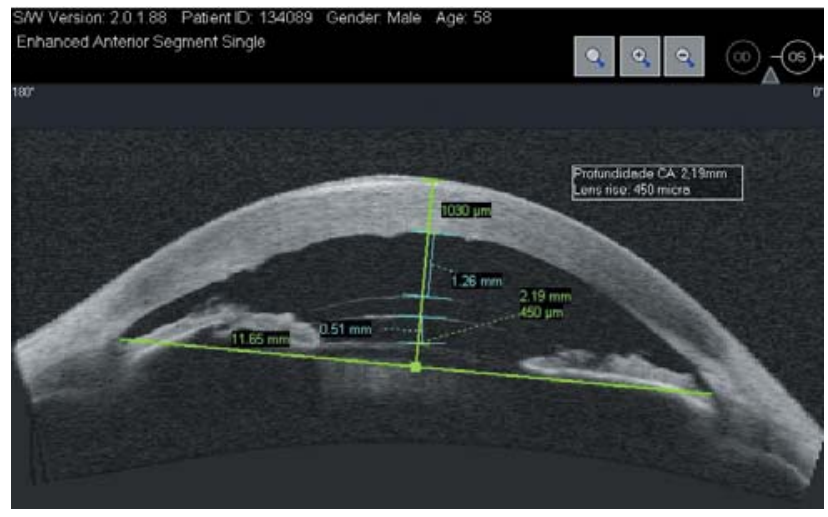

Figura 10: OCT de segmento anterior de paciente com descompensação de córnea e implante de LIO Artisan para hipermetropia (observe a espessura corneana de $1.030 \mu \mathrm{m}$ e a profundidade de câmara anterior atual de $2,19 \mathrm{~mm}$ )

der estar relacionada a um caso que evoluiu com perda endotelial severa aos 3 anos de pós-operatório ${ }^{(16)}$.

As descentrações observadas no pós-operatório de lentes de fixação iriana podem ser classificadas em precoces (diagnosticadas no pós-operatório inicial e relacionada ao ato cirúrgico, podendo ser superior ou inferior) ou tardias (geralmente inferior e associada à atrofia progressiva de íris no local de seu encravamento) (48). Pérez-Santonja et al. encontraram descentração de 0 a $0,25 \mathrm{~mm}$ em $31 \%$ (10/32) dos casos implantados com lente Artisan; de 0,26 a $0,50 \mathrm{~mm}$ em $25 \%$ (8/32); de 0,51 a $0,75 \mathrm{~mm}$ em $28 \%$ (9/32), e de 0,76 a $1,00 \mathrm{~mm}$ em $15 \%$ (5/ 32). Correlação estatisticamente significante foi observada entre a quantidade de descentração e a presença de queixas subjetivas de visão de halos ${ }^{(40)}$. Descentração da LIO igual ou superior a $0,50 \mathrm{~mm}$ foi observada em 14 olhos $(29,1 \%)$ do estudo de Menezo et al (37). Reposicionamento da LIO Artiflex por problemas de centralização foi necessário em 1,03\% dos casos (3/290) no estudo europeu(25). Deslocamento traumático da LIO já foi reportado ${ }^{(30,31,43,49)}$, devendo ser prontamente resolvido pelo risco de toque endotelial e edema (Figura 12).

\section{Atrofia de íris \\ Complicação observada no local da fixação da LIO à íris pode apresentar intensidade variável (Figura 13), tendo sido encontrada em 29 dos 32 olhos implantados com lentes Artisan (90,6\%) por Pérez-Santonja et al. Em um destes, o háptico nasal se soltou tendo sido necessária nova intervenção cirúrgica para reposicionamento da LIO (40). Menezo et al. relataram 22 casos $(23,4 \%)$ com atrofia de íris no local da fixação, e três $(3,2 \%)$ com perfuração da íris pelos hápticos. Um destes necessitou de reintervenção cirúrgica por luxação da LIO ${ }^{(37)}$.}

\section{Outras complicações}

Complicações como hipertensão ocular e bloqueio pupilar já foram descritas no pós-operatório de lentes fácicas de câmara anterior (16,30,40,43,50). A remoção completa do viscoelástico ao término da cirurgia e

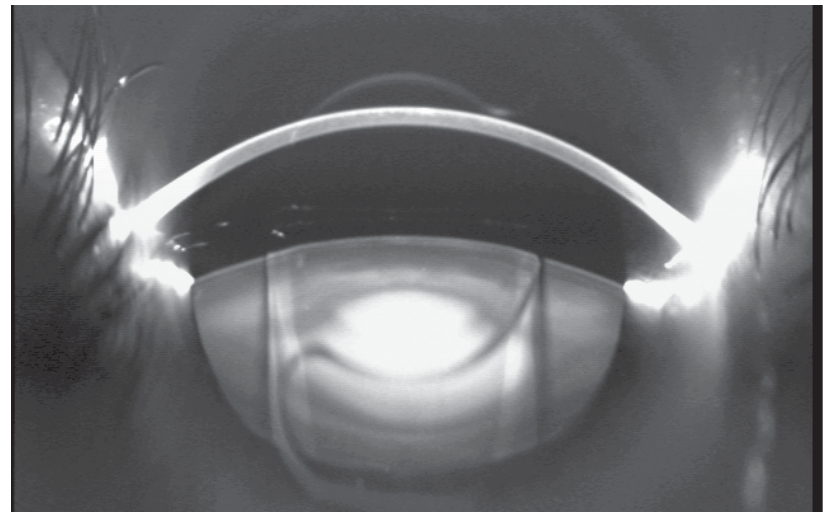

Figura 11: Sistema Scheimpflug de um olho com catarata nuclear e implante de lente fácica rígida de suporte angular

iridotomia periférica pré-operatória ou iridectomia intraoperatória são passos importantes para prevenir o bloqueio pupilar. Na LIO Acrysof Cachet a realização da iridectomia periférica não é mandatória, não tendo sido observado bloqueio pupilar em nenhum dos 390 casos operados segundo Knorz et al. ${ }^{(16)}$. Neste estudo, a iridotomia foi realizada em apenas 1 olho a critério do cirurgião por hipertensão ocular associada a retenção de viscoelástico na câmara anterior ${ }^{(16)}$. Síndrome de Urretz-Zavalia já foi relatada com as lentes fácicas de câmara anterior de suporte angular e fixação iriana ${ }^{(51-53)}$, inclusive com a Artiflex ${ }^{(25)}$.

Poucos casos de síndrome tóxica do segmento anterior (TASS: toxic anterior segment syndrome) ocorreram com lentes de fixação iriana ${ }^{(54,55)}$, tendo sido relacionada ao viscoelástico utilizado em um deles ${ }^{(54)}$. O risco de infecção intraocular sempre existe, já tendo sido reportado um caso de endoftalmite ${ }^{(56)}$.

\section{ConClusão}

Os implantes fácicos de câmara anterior atualmente disponíveis apresentam-se como uma boa opção para correção cirúrgica de altas ametropias, com resultados satisfatórios em relação a previsibilidade, eficácia, estabilidade e segurança. A avaliação pré-operatória é de fundamental importância para seleção dos casos considerados ideais para a cirurgia. A possibilidade de associação com procedimentos fotoablativos permite o ajuste do efeito refrativo obtido. O desenvolvimento e utilização de lentes dobráveis facilitam o procedimento cirúrgico e diminuem as alterações refracionais secundárias à incisão.

\section{RefERÊNCIAS}

1. Dada T, Sudan R, Sinha R, Ray M, Sethi H, Vajpayee RB. Results of laser in situ keratomileusis for myopia of -10 to -19 diopters with a Technolas 217 laser. J Refract Surg. 2003;19(1):44-7. 


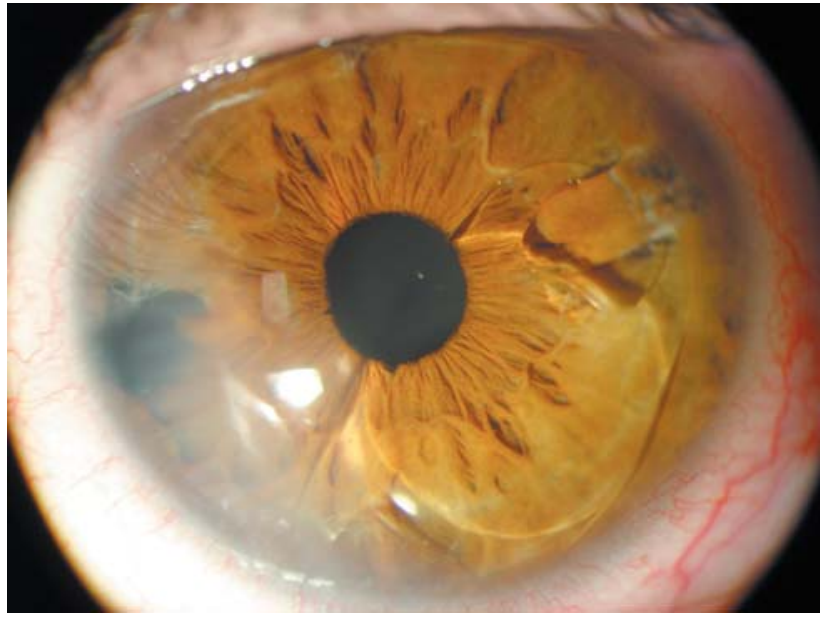

Figura 12: Deslocamento traumático de lente Artisan com edema localizado na periferia da córnea

2. Goldberg MF. Clear lens extraction for axial myopia: an appraisal. Ophthalmology. 1987;94:571-82.

3. Strampelli B. Sopportabilitá di lenti acriliche in camera anteriore nella afachia e nei vizi de refrazione. Ann Ottamol Clin Ocul. 1954;80:75-82.

4. Barraquer J. Anterior chamber plastic lenses. Results and conclusions from five years' experience. Trans Ophthalmol Soc U K. 1959;79:393-424.

5. Drews RC. The Barraquer experience with intraocular lenses: 20 years later. Ophthalmology. 1982;89:386-93.

6. Baikoff G, Joly P. Comparison of minus power anterior chamber intraocular lenses and myopic epikeratoplasty in phakic eyes. Refract Corneal Surg. 1990;6:252-60.

7. de Souza RF, Forseto A, Nosé R, Belfort R, Jr., Nosé W. Anterior chamber intraocular lens for high myopia: five year results. J Cataract Refract Surg. 2001 Aug;27(8):1248-53.

8. Vanzella LL, Nosé W, Schor P, Allemann N, Nosé RM, Chamon W. Implante de lente de câmara anterior para correção da miopia em olhos fácicos. Arq Bras Oftalmol. 1997;60:162-7.

9. Allemann N, Chamon W, Tanaka HM, Mori ES, Campos M, Schor P, et al. Myopic angle-supported intraocular lenses: twoyear follow-up. Ophthalmology. 2000 Aug;107(8):1549-54.

10. de Souza RF, Allemann N, Forseto A, Barros PS, Chamon W, Nosé W. Ultrasound biomicroscopy and Scheimpflug photography of angle-supported phakic intraocular lens for high myopia. J Cataract Refract Surg. 2003 Jun;29(6):1159-66.

11. Javaloy J, Alio JL, Iradier MT, Abdelrahman AM, Javaloy T, Borras F. Outcomes of ZB5M angle-supported anterior chamber phakic intraocular lenses at 12 years. J Refract Surg. 2007 Feb;23(2):147-58.

12. Guell JL, Morral M, Kook D, Kohnen T. Phakic intraocular lenses part 1: historical overview, current models, selection criteria, and surgical techniques. J Cataract Refract Surg. 2010 Nov;36(11):1976-93

13. Kohnen T, Knorz MC, Cochener B, Gerl RH, Arne JL, Colin J, et al. AcrySof phakic angle-supported intraocular lens for the correction of moderate-to-high myopia: one-year results of a multicenter European study. Ophthalmology. 2009 Jul;116(7):1314-21, 21 e1-3.

14. Kohnen T, Klaproth OK. Three-year stability of an anglesupported foldable hydrophobic acrylic phakic intraocular lens evaluated by Scheimpflug photography. J Cataract Refract Surg. 2010 Jul;36(7):1120-6.

15. Huang D, Schallhorn SC, Sugar A, Farjo AA, Majmudar PA, Trattler WB, et al. Phakic intraocular lens implantation for the correction of myopia: a report by the American Academy of Ophthalmology. Ophthalmology. 2009 Nov;116(11):2244-58.

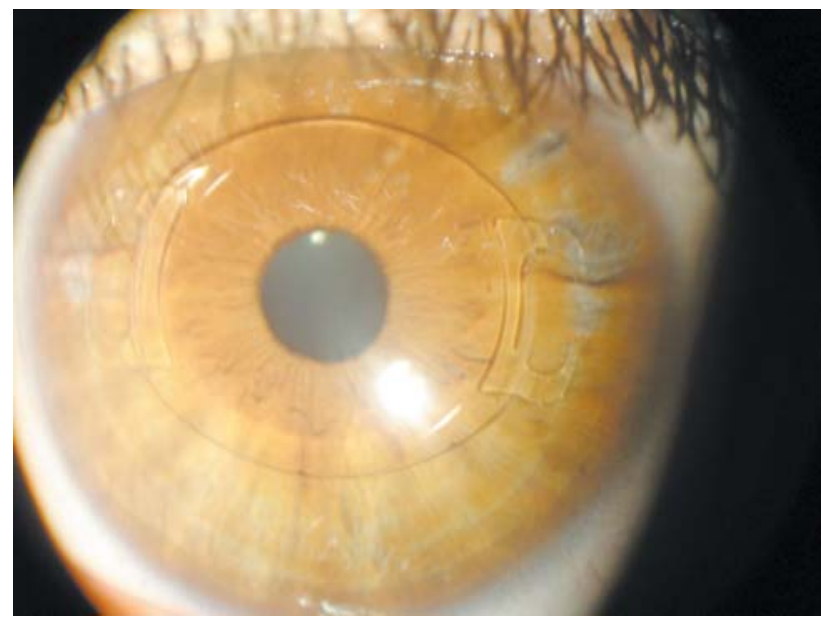

Figura 13: Pós-operatório de implante de lente Artiflex com atrofia iriana no local da fixação

16. Knorz MC, Lane SS, Holland SP. Angle-supported phakic intraocular lens for correction of moderate to high myopia: Three-year interim results in international multicenter studies. J Cataract Refract Surg. 2011 Mar;37(3):469-80.

17. Worst JG. Iris claw lens. J Am Intraocul Implant Soc. 1980;6(2):166-7.

18. Fechner PU, van der Heijde GL, Worst JG. [Intraocular lens for the correction of myopia of the phakic eye]. Klin Monatsbl Augenheilkd. 1988;193(1):29-34.

19. Worst JG, van der Veen G, Los LI. Refractive surgery for high myopia. The Worst-Fechner biconcave iris claw lens. Doc Ophthalmol. 1990 Oct;75(3-4):335-41.

20. Tehrani M, Dick HB. [Implantation of an ARTISANtrade mark toric phakic intraocular lens to correct high astigmatism after penetrating keratoplasty]. Klin Monbl Augenheilkd. 2002 Mar;219(3):159-63.

21. Dick HB, Alio J, Bianchetti M, Budo C, Christiaans BJ, ElDanasoury MA, et al. Toric phakic intraocular lens: European multicenter study. Ophthalmology. 2003;110(1):150-62.

22. van der Heijde GL. Some optical aspects of implantation of an IOL in a myopic eye. Eur J Implant Refract Surg. 1989;1:245-8.

23. Kohnen T, Thomala MC, Cichocki M, Strenger A. Internal anterior chamber diameter using optical coherence tomography compared with white-to-white distances using automated measurements. J Cataract Refract Surg. 2006 Nov;32(11):1809-13.

24. Saxena R, Boekhoorn SS, Mulder PG, Noordzij B, van Rij G, Luyten GP. Long-term follow-up of endothelial cell change after Artisan phakic intraocular lens implantation. Ophthalmology. 2008 Apr;115(4):608-13 e1.

25. Dick HB, Budo C, Malecaze F, Guell JL, Marinho AA, Nuijts RM, et al. Foldable Artiflex phakic intraocular lens for the correction of myopia: two-year follow-up results of a prospective European multicenter study. Ophthalmology. 2009 Apr;116(4):671-7.

26. Baikoff G, Bourgeon G, Jodai HJ, Fontaine A, Lellis FV, Trinquet L. Pigment dispersion and Artisan phakic intraocular lenses: crystalline lens rise as a safety criterion. J Cataract Refract Surg. 2005 Apr;31(4):674-80.

27. Stulting RD, John ME, Maloney RK, Assil KK, Arrowsmith PN, Thompson VM. Three-year results of Artisan/Verisyse phakic intraocular lens implantation. Results of the United States Food And Drug Administration clinical trial. Ophthalmology. 2008 Mar;115(3):464-72 e1. 
28. Zaldivar R, Davidorf JM, Oscherow S, Piezzi V. Combined posterior chamber phakic intraocular lenses and laser in situ keratomileusis: Bioptics for extreme myopia. J Refract Surg. 1999;15:299-308.

29. Alio JL, Mulet ME, Shalaby AM. Artisan phakic iris claw intraocular lens for high primary and secondary hyperopia. J Refract Surg. 2002;18(6):697-707.

30. Budo C, Hessloehl JC, Izak M, Luyten GP, Menezo JL, Sener BA, et al. Multicenter study of the Artisan phakic intraocular lens. J Cataract Refract Surg. 2000;26(8):1163-71.

31. Guell JL, Morral M, Gris O, Gaytan J, Sisquella M, Manero F. Five-year follow-up of 399 phakic Artisan-Verisyse implantation for myopia, hyperopia, and/or astigmatism. Ophthalmology. 2008 Jun;115(6):1002-12.

32. Applegate RA, Howland HC. Magnification and visual acuity in refractive surgery. Arch Ophthalmol. 1993;111:1335-42.

33. Malecaze FJ, Hulin H, Bierer P, Fournie P, Grandjean H, Thalamas $\mathrm{C}$, et al. A randomized paired eye comparison of two techniques for treating moderately high myopia: LASIK and artisan phakic lens. Ophthalmology. 2002;109(9):1622-30.

34. El Danasoury MA, El Maghraby A, Gamali TO. Comparison of irisfixed Artisan lens implantation with excimer laser in situ keratomileusis in correcting myopia between -9.00 and -19.50 diopters: a randomized study. Ophthalmology. 2002;109(5):955-64.

35. Kohnen T, Kook D, Morral M, Guell JL. Phakic intraocular lenses: part 2: results and complications. J Cataract Refract Surg. 2010 Dec;36(12):2168-94.

36. Van Cleynenbreugel H. Late postoperative complications of backward implantation of a Vivarte phakic intraocular lens. J Cataract Refract Surg. 2007 Aug;33(8):1474-6.

37. Menezo JL, Avino JA, Cisneros A, Rodriguez-Salvador V, Martinez-Costa R. Iris claw phakic intraocular lens for high myopia. J Refract Surg. 1997;13(6):545-55.

38. Fechner PU, Strobel J, Wicchmann W. Correction of myopia by implantation of a concave Worst-iris claw lens into phakic eyes. Refract Corneal Surg. 1991;7(4):286-98.

39. Perez-Santonja JJ, Iradier MT, Benitez del Castillo JM, Serrano JM, Zato MA. Chronic subclinical inflammation in phakic eyes with intraocular lenses to correct myopia. J Cataract Refract Surg. 1996 Mar;22(2):183-7.

40. Perez-Santonja JJ, Bueno JL, Zato MA. Surgical correction of high myopia in phakic eyes with Worst-Fechner myopia intraocular lenses. J Refract Surg. 1997 May-Jun;13(3):268-81; discussion 81-4.

41. Kleinmann G, Apple DJ, Mackool RJ. Recurrent iritis after implantation of an iris-fixated phakic intraocular lens for the correction of myopia Case report and clinicopathologic correlation. J Cataract Refract Surg. 2006 Aug;32(8):1385-7.

42. Menezo JL, Martinez MC, Cisneros AL. Iris-fixated Worst claw versus sulcus-fixated posterior chamber lenses in the absence of capsular support. J Cataract Refract Surg. 1996;22(10):1476-84.

43. Menezo JL, Cisneros AL, Rodriguez-Salvador V. Endothelial study of iris-claw phakic lens: four year follow-up. J Cataract Refract Surg. 1998 Aug;24(8):1039-49.
44. Landesz M, Worst JG, van Rij G. Long-term results of correction of high myopia with an iris claw phakic intraocular lens. J Refract Surg. 2000;16(3):310-6.

45. Maloney RK, Nguyen LH, John ME. Artisan phakic intraocular lens for myopia:short-term results of a prospective, multicenter study. Ophthalmology. 2002;109(9):1631-41.

46. Alio JL, de la Hoz F, Ruiz-Moreno JM, Salem TF. Cataract surgery in highly myopic eyes corrected by phakic anterior chamber angle-supported lenses(1). J Cataract Refract Surg. 2000 Sep;26(9):1303-11.

47. Chen LJ, Chang YJ, Kuo JC, Rajagopal R, Azar DT. Metaanalysis of cataract development after phakic intraocular lens surgery. J Cataract Refract Surg. 2008 Jul;34(7):1181-200.

48. Nosé W, Forseto AS, Rehder JR. Lentes de suporte iriano. In: Alves MR, Chamon W, Nosé W, editors. Cirurgia Refrativa Conselho Brasileiro de Oftalmologia. Rio de Janeiro: Cultura Médica; 2003. p. 446-52.

49. Yoon H, Macaluso DC, Moshirfar M, Lundergan M. Traumatic dislocation of an Ophtec Artisan phakic intraocular lens. J Refract Surg. 2002;18(4):481-3.

50. Fechner PU. Iris claw lens. J Cataract Refract Surg. 1991;17(6):860-1.

51. Yuzbasioglu E, Helvacioglu F, Sencan S. Fixed, dilated pupil after phakic intraocular lens implantation. J Cataract Refract Surg. 2006 Jan;32(1):174-6.

52. Plainer S, Wenzl E, Saalabian AA, Wohlfart C, Vidic B, ElShabrawi Y, et al. Long-term follow-up with I-care phakic IOLs. Br J Ophthalmol. 2010 Oct 8.

53. Park SH, Kim SY, Kim HI, Yang SW. Urrets-Zavalia syndrome following iris-claw phakic intraocular lens implantation. J Refract Surg. 2008 Nov;24(9):959-61.

54. Kremer I, Levinger E, Levinger S. Toxic anterior segment syndrome following iris-supported phakic IOL implantation with viscoelastic Multivisc BD. Eur J Ophthalmol. 2010 MarApr;20(2):451-3.

55. Moshirfar M, Whitehead G, Beutler BC, Mamalis N. Toxic anterior segment syndrome after Verisyse iris-supported phakic intraocular lens implantation. J Cataract Refract Surg. $2006 \mathrm{Jul} ; 32(7): 1233-7$.

56. Perez-Santonja JJ, Ruiz-Moreno JM, de la Hoz F, Giner-Gorriti C, Alio JL. Endophthalmitis after phakic intraocular lens implantation to correct high myopia. J Cataract Refract Surg. 1999 Sep;25(9):1295-8.

\section{Autor correspondente:}

Walton Nosé

Av. República do Líbano, nº1034

CEP 04502-001 - São Paulo (SP), Brasil

Fax: (11)3884-7680

e-mail:wnose@eyeclinic.com.br 